\title{
A Simple Method for Determination of Switched Capacitor Bank in Power Distribution Systems
}

\author{
Milad Dowlatshahi and Davood Pahlavan* \\ Islamic Azad University, Khomeinishahr Branch \\ Khomeinishahr Azad University \\ Isfahan, Iran
}

Received 26.01.2015, received in revised form 04.02.2015, accepted 29.08.2015

\begin{abstract}
This paper proposes an efficient and novel technique for assessment of the direction of switched capacitor bank as well as estimating its distance from the monitoring location in real distribution systems. At first, the proposed method determines the direction of switched capacitor banks based on the slope of the voltage and current space vectors immediately after the capacitor switching instant. Afterward, the exact location of switched capacitor from the monitoring location is determined by estimating the feeder line inductance using first sample magnitude of voltage and current space vector after the switching instant. The discrete wavelet transform (DWT) is also used to detect the exact instant of switching as well as the exact values of voltage and current caused by switching. In this paper, the capabilities of the proposed method are evaluated in various state of switching (normal, Back-To-Back), presence of stochastic nonlinear load and different sampling rate. The effectiveness of the proposed technique is demonstrated with system data obtained from IEEE-13 bus feeders modelled in PSCAD/EMTDC. Simulation results demonstrate the validity and effectiveness of the proposed method considering accepTable error in locating the switched capacitor bank in distribution systems.
\end{abstract}

Keywords: capacitor switching, distance estimation, power quality, stochastic nonlinear load, slope based method, wavelet transform.

DOI: $10.17516 / 1999-494 X-2015-8-8-970-996$.

(C) Siberian Federal University. All rights reserved

* Corresponding author E-mail address: dolatshahi@iaukhsh.ac.ir 


\title{
Простой метод для определения
}

\section{включения групп конденсаторов \\ в системах распределения энергии}

\author{
М. Довлатсхахи, Д. Пахлаван \\ Исламский университет Азад, Кхомеинисхахр филиал \\ Кхомеинисхахр Азад университет \\ Исфахан, Иран
}

\begin{abstract}
Эта статья предлагает эффективный и новый метод для оценки направления коммутируемых конденсаторных групп, а также оиенки расстояния от места наблюдения в реальных системах распределения. Во-первых, предложенный способ определяет направление коммутируемых конденсаторов, основанных на диаграммах пространственных векторов напряжения и тока, сразу после момента переключения конденсатора. Далее точное расположение включенного конденсатора от места мониторинга определяется путем оиенки индуктивности фидерной линии с использованием первого образиа пространственного вектора величины напряжения и тока после момента переключения. Дискретное вейвлет-преобразование (DWT) также используется для выявления точного момента переключения и для точных значений напряжения и тока, вызванных переключением. В этой статье возможности предложенного метода оиенены в различных вариантах расположения при переключении (нормально, спина к спине), наличия стохастической нелинейной нагрузки и различной частотой дискретизации. Эффективность предложенной методики сопоставляется с данными, полученными из системы IEEE-13bus фидеров, смоделированных в PSCAD / EMTDC. Результаты моделирования показывают обоснованность и эффективность предложенного метода с учетом приемлемой ошибки в поиске включения конденсаторов в системах распределения.
\end{abstract}

Ключевые слова: переключение конденсаторов, оценка расстояния, качество питания, стохастическая нелинейная нагрузка, базовый метод, вейвлет-преобразование.

\section{Introduction}

The capacitor banks in power system are used to improve the voltage profile, provide the reactive power, improve the power factor, reduce the power losses and increase the system capacity. Regarding the wide use and the repetitive switching of the switching capacitor banks, the transient states resulted from their switching have negative effects on power quality and equipment involved in distribution systems [1]. The examples of some destructive effects in distribution systems are transient disturbances which lead to the tripping of adjusTable speed drives, failure of control and protective equipment, power electrical tools and all sensitive equipment in the power system [2]. Therefore, to predict and enhance the power quality, at the first place, it is necessary to identify the transient state of capacitor bank switching by use of a limited number of power quality meter (PQM) tools and then determining location of the turbulence origin. The focus of this paper is on development of a fast method for exact locating a switched capacitor in a power system. Until present, in order to determine the location of capacitor bank, the various techniques have been under taken. In [3], an introduced method to determine the switching capacitor bank location by use of line impedance and resonant frequency. However, this method requires solving the dynamic equations of the system and it is not proper for real power system. [4], a proposed method to track the transient state of the capacitor by use of indicators for 
energy and power changes resulted from the current and voltage transient. However, the considering issus have some approximation which may cause to unaccepTable error in distance estimation of SCB. The backward-Kalman filter was applied in [5] to estimate the location of switched capacitor bank. Application of this method requires solving the dynamic equations in the power system and it seems to be impractical for real distribution systems. The capacitor bank determined approximately in [6] by use of the initial voltage changes. However, proposed method for those capacitor banks which were located at the downstream of the monitoring location and it would be unreliable in real distribution systems. In [7], using the signs of voltage and current waveform gradients as well as power factor changes, a method for upstream and downstream of the monitoring location is proposed. This method relies on the measurement of the system power factor while it is practically impossible to measure precisely in real power systems. Moreover this method the location of capacitor switching is not accurate enough. Considering voltage signed by hybrid principle component analysis proposed in [8]. In this method, a classification system composed of two neural networks which used to reduce the input data, while in the practical point of view this method in a large system is complicated. A method based on the artificial neural network (ANN) introduced in [9]. In which method, the transient duration and the current energy of transient state resulted from two levels of the discrete wavelet transform are used to train the neural network. A method is proposed in [10] to assessment of the direction and estimating the distance between the capacitor bank and monitoring location by the transient current and voltage of each phase. The efficiency and the precision of this method is totally depend on the switching instant so that the switching at each time except for the instant of the crossing the voltage at peak, will lead to error in determining the direction and distance estimation. However the introduced index (k) for each phase at every instant of switching would be different. Moreover this, the effect of the laterals on the distance estimation algorithm was ignored. The capacitor bank location determined in [11] by use of the magnitude of the voltage and current space vector. This method just determined where the capacitor bank exist but it couldn't locate exactly the switched capacitor bank in the mentioned branch and just determines approximately the range of switching capacitor bank, while it is possible that there are several capacitors candidate for switching in the specified range and at the intended instant.

In this article, a novel and efficient method to assessment of the direction and location of switched capacitor bank in presence of stochastic nonlinear loads in the real distribution system is introduced. Problem and hypothesis description is indicated in (2), the determining the direction algorithm of switched capacitor bank will be introduce in (3) and the method to estimate the distance from monitoring location will proposed in (4). The efficiency and authenticity of the proposed method in IEEE-13 bus network [12] is designed and studied by PSCAD software [13] and the results of these simulations are shown in section (5).

\section{Problem and Hypothesis Description}

This article focuses on designing a fast algorithm to locate the switched capacitor bank by use of the data obtained from the transient state resulted from capacitor bank's switching. In this method, the switching capacitor bank is considered without any control mechanism for reducing transient overvoltage and the inrush current due to the switching. Switching transients without control mechanisms are more likely to cause power quality problems than those with control mechanisms. Switching without control mechanisms can well represent the most of capacitor banks in distribution feeders. Fig. 1 shows the 
Block-Diagram of the proposed algorithm. As it's shown in this fig, detection and classification of the disturbance origin in the transient state [14-16], as well as, the direction in which the capacitor bank is switched and also its distance respect to the monitoring location is determined by extracting the necessary data from $(\mathrm{PQM})$.

The single-line diagram of the sample distribution network with the switching capacitor bank is shown in Fig. 2. In this network, branch (2) represents a direction where a switching capacitor bank is located and branch (3) indicates an equivalent circuit of all branches which are not located in the direction of switching capacitor bank. Therefore, each arbitrary distribution network, like a sample distribution network in Fig. 2, can be considered as two branches that one is a switching capacitor bank feeder and the other is the equivalent circuit of those branches which is not locate in the path where feeding the switching capacitor bank. Basically, the frequency of the power system is much lower than the switching frequency. Therefore, at the instant of switching, Vsc is considered as constant.

When a capacitor considering no initial charge is switched on, it can be modelled as short circuit and therefore there will be a sudden decrease in network voltage level $\left(\mathrm{PQM}_{1,2}\right)$ due to continuity of the

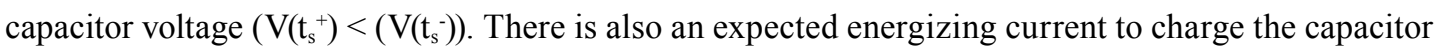
bank immediately after the switching instant along the direction of real power flow. As it's represented by Fig. 3, due to the capacitor bank charge, the current will be increased in those branches which are supplying capacitor bank and vice versa, it will be reduced in other branches. These changes are demonstrated considering equation (1) and (5):

$$
\left\{\begin{array}{l}
i_{2}\left(t_{s}^{-}\right)=i_{1}\left(t_{s}^{-}\right) \times \frac{Z_{3}+Z_{L 1}}{Z_{3}+Z_{L 1}+Z_{2}+Z_{4}+Z_{L 2}} \\
i_{2}\left(t_{s}^{+}\right)=i_{1}\left(t_{s}^{+}\right) \times \frac{Z_{3}+Z_{L 1}}{Z_{3}+Z_{L 1}+Z_{2}}
\end{array} \Rightarrow i_{2}\left(t_{s}^{+}\right)>i_{2}\left(t_{s}^{-}\right)\right.
$$

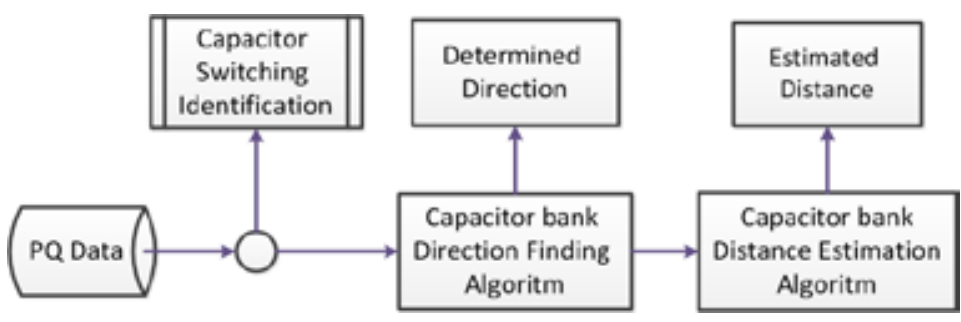

Fig. 1. General algorithm of the proposed method

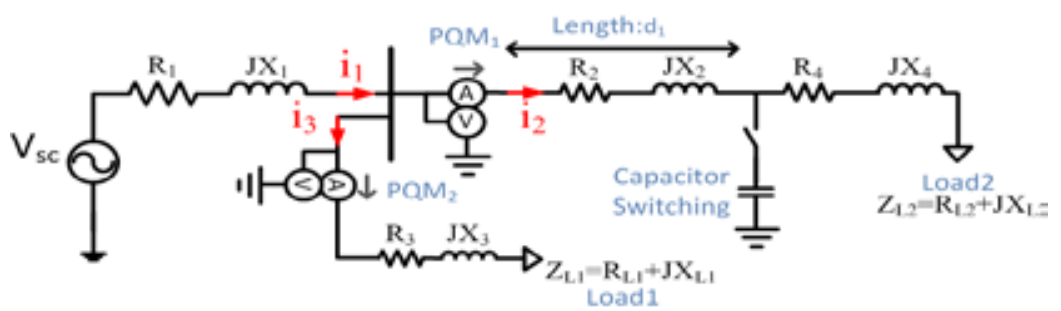

Fig. 2. Sample distribution network 


$$
\begin{aligned}
& L_{e q_{3}}=L_{3}+L_{L_{1}} \quad, \quad R_{e q_{3}}=R_{3}+R_{L_{1}} \\
& \left\{\begin{array}{l}
V\left(t_{s}^{-}\right)=L_{e q_{3}} \frac{d i_{3}\left(t_{s}^{-}\right)}{d t}+R_{e q_{3}} i_{3}\left(t_{s}^{-}\right) \\
V\left(t_{s}^{+}\right)=L_{e q_{3}} \frac{d i_{3}\left(t_{s}^{+}\right)}{d t}+R_{e q_{3}} i_{3}\left(t_{s}^{+}\right)
\end{array}, \Delta V\left(t_{s}\right)=V\left(t_{s}^{+}\right)-V\left(t_{s}^{-}\right)<0\right. \\
& \Delta V\left(t_{s}\right)=L_{e q_{3}} \frac{d \Delta i_{3}}{d t}+R_{e q_{3}} \Delta i_{3}
\end{aligned}
$$

Because at switching instant $X>>R$ :

$$
\begin{aligned}
& \left\{\begin{array}{l}
\Delta V\left(t_{s}\right)=L_{e q 3} \frac{d \Delta i_{3}}{d t} \\
\Delta V\left(t_{s}\right)<0
\end{array} \Rightarrow \Delta i_{3}<0\right. \\
& \Delta i_{3}=i_{3}\left(t_{s}^{+}\right)-i_{3}\left(t_{s}^{-}\right)<0 \quad \Rightarrow \quad i_{3}\left(t_{s}^{+}\right)<i_{3}\left(t_{s}^{-}\right)
\end{aligned}
$$

It is noteworthy that, the amount of voltage drop in the system at the monitoring location depends on the impedance of the line between switched capacitor bank and monitoring location so that the shorter distance between the switched capacitor bank and the monitoring location (PQM1), would cause the $(\mathrm{V}(\mathrm{ts}+))$ to be closer to zero which is shown in Fig. 4

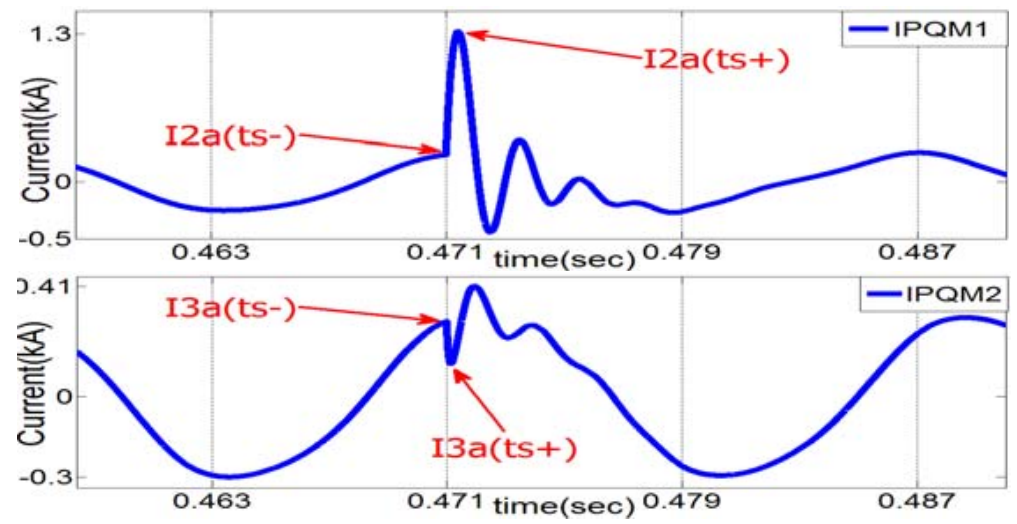

Fig. 3. Waveform of the currents resulted from the capacitor bank switching in the sample network

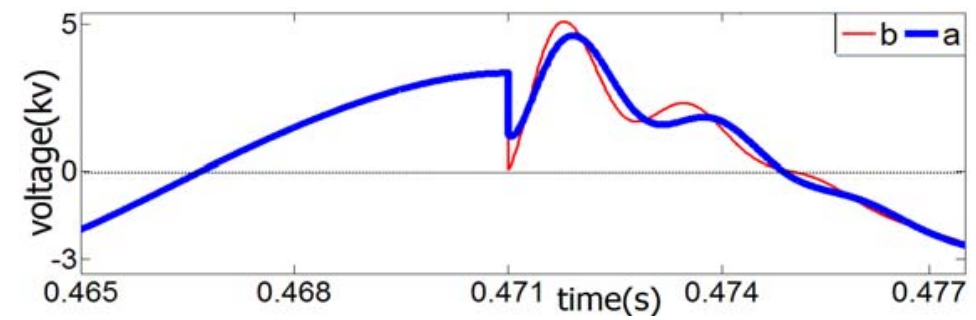

Fig. 4. Waveform of the currents resulted from the capacitor bank switching (a) considering the line between monitoring location and capacitor, (b) without line between monitoring location and capacitor 


\section{Switched Capacitor Bank Direction Determination}

As a result of capacitor bank switching, the changes in the current and the voltage at the beginning of the transient state may have negative or positive slopes. The slope-based method, determines the switched capacitor bank location respect to the monitoring location, immediately after the switching by use of the current and voltage signals measured by PQM.

\subsection{Direction determination using the slope of the current}

and the voltage of each phase in the transient state

In this section, a method is introduced which determines the direction where the capacitor bank is switched, using the changes in the current and the voltage of each phase immediately before and after the switching instant. The slope-based method indicates that the slope of the current and the voltage of each phase immediately before and after switching will have the opposite polarities for the monitoring location placed in line and branches which feed the capacitor bank and identical polarities in the other lines and branches the magnitude of changes in current and voltage waveforms depend on the size and location of the switched capacitor bank [10].

$$
D_{V I}=\left(V\left(t_{s}^{+}\right)-V\left(t_{s}^{-}\right)\right) \times\left(i\left(t_{s}^{+}\right)-i\left(t_{s}^{-}\right)\right)
$$

If switching occurs at the instant $\mathrm{t}=\mathrm{ts}$, $\mathrm{t}=\mathrm{ts}-$ represents the sampling time before the switching instant and $\mathrm{t}=\mathrm{ts}+$ shows sampling time after switching instant. Therefore, considering the slope of the current and voltage for each phase in the transient state and comparison of its changes, the direction in which the capacitor bank is switched can be found.

Figs. 5, 6 shows the switching waveform of the transient current and voltage of the phase a at the instant of crossing the voltage at peak ts $=0.471$ (state (a)) and at the instant of crossing voltage at around zero ts $=0.283$ (state (b)) in the distribution system.
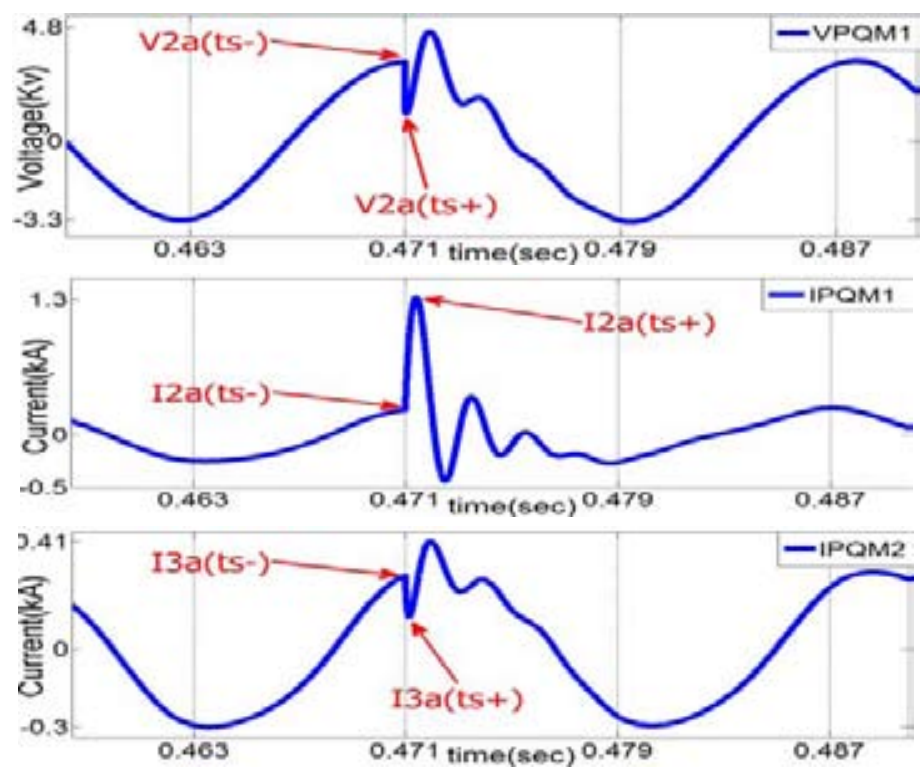

Fig. 5. Waveform of the transient voltage and current around the instant of crossing the voltage at peak (state (a)) 


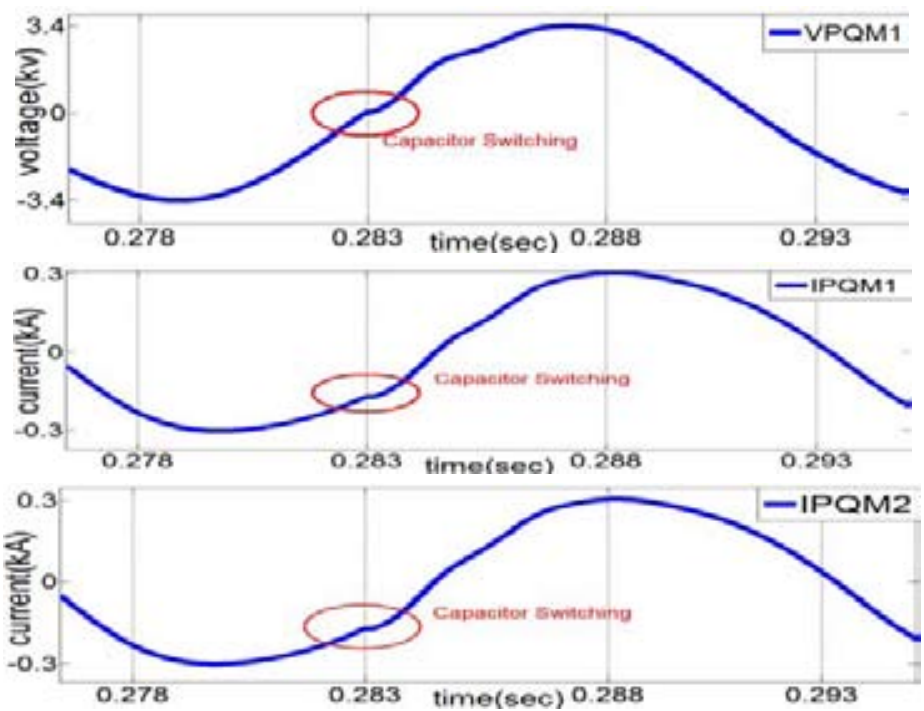

Fig. 6. Waveform of the transient voltage and current around the instant of crossing the voltage at around zero (state (b))

Table $1 . \mathrm{D}_{\mathrm{VI}}$ index for the sample network considering two different instant

\begin{tabular}{|c|c|c|c|c|}
\hline \multirow{2}{*}{ Branch } & \multicolumn{2}{|c|}{ state(a) } & \multicolumn{2}{c|}{ state(b) } \\
\cline { 2 - 5 } & $\boldsymbol{D}_{V I}$ & Sign & $\boldsymbol{D}_{V I}$ & Sign \\
\hline $\mathbf{1}$ & -2.31 & Negative & -0.014 & Negative \\
\hline $\mathbf{2}$ & $\underline{\mathbf{2 . 3 8}}$ & $\underline{\text { Negative }}$ & -0.01 & Negative \\
\hline $\mathbf{3}$ & +0.348 & Posetive & -0.003 & \\
\hline
\end{tabular}

According to Fig. 2, since the capacitor bank located in the branch (2), the $\mathrm{D}_{\mathrm{VI}}$ index in the branches (1) and (2) are negative while in the branch (3) is positive and magnitude of the $\mathrm{D}_{\mathrm{VI}}$ index in the branch (2) is larger than other branches. it can be seen in Table 1 that direction determination at the instant of crossing the voltage at peak (state (a)) is correct, however, when the switching instant is close to the zero-crossing point of the waveform (state (b)), the direction finding is not accomplished correctly. Since the polarity of the index $\left(\mathrm{D}_{\mathrm{VI}}\right)$ is negative in all branches (all three branches feed the capacitor bank) and the value of the index $\left(\mathrm{D}_{\mathrm{VI}}\right)$ in branch (1) is larger than the other branches (the capacitor is located in branch (1)), while according to Fig. 2, the capacitor is located in branch (2). Therefore, it can be concluded that assessment of the direction of switched capacitor bank in the described method based on the gradients of the voltage and current in transient state in each phase is totally dependent on the switching instant of the capacitor bank.

In the slope-based methods, when the switching instant is close to the zero-crossing point of the waveform, the transient state resulted from switching is too small [11] and determining sign of the $\mathrm{D}_{\mathrm{VI}}$ index is not authentic in this situation and should be determined based on the other phases. Also in real situation, in the environments infected with harmonics and noises, current and voltage waveforms are no more sinusoidal hence, determining the slope of the capacitor bank switching at 
the instant of crossing the signal at zero is complicated and fallacious because of the small transient state.

\subsection{Switched capacitor bank determination using the slope of voltage and current space vectors}

A method which proposed in [11] determined the direction of the switched the capacitor bank by the slope of the voltage and current space vector. The main advantage of the space vector method compared to other filter-based methods is that this method is less dependence on switching instant because all three-phase quantities contribute to the magnitude of the space vector and works considering a quantity that represents contributions of the three-phase measured waveforms. The other advantage of this method is its algebraic nature which yield facilitates its function and implementation. Fig. 7 shows a block diagram based on the space vector.

The magnitude of space vector of a value for three phases $\left(f_{\mathrm{abc}}\right)$ is calculated using equation $(7)$. The symbol II.II represents a quadratic norm function applied to the components of voltages and currents in an arbitrary reference frame (e.g. qdo- or $\alpha \beta o$-frame). The advantage of using IIvll and Ilill instead of phase quantities is that the space vector quantities encounter the information of all three phases at the switching instant. The measured abc voltages and currents are introduced to a space-vector calculator, which provides two non-zero quantities corresponding to the voltages and currents. In this method, finally the magnitude of the space vector is used in the reference $\alpha$ Bo to determine the direction of switched capacitor bank. The most important advantage of using $\alpha \beta$ o compared that dqo frame is that it enables calculating the magnitudes of the voltage and current vectors without using a phase-locked loop (PLL) for synchronisation, In this frame, the abc components are directly converted to the fixed transformation matrix $\mathrm{K}_{0}[17]$.

$$
\begin{aligned}
& K_{0}=\frac{2}{3}\left[\begin{array}{ccc}
1 & -0.5 & -0.5 \\
0 & -\frac{\sqrt{3}}{2} & \frac{\sqrt{3}}{2} \\
0.5 & 0.5 & 0.5
\end{array}\right] \quad, \quad\left[f_{d q o}\right]=\left[K_{0}\right] \cdot\left[f_{a b c}\right] \\
& \|f\|=\sqrt{f_{d}^{2}+f_{q}^{2}+f_{0}^{2}}
\end{aligned}
$$

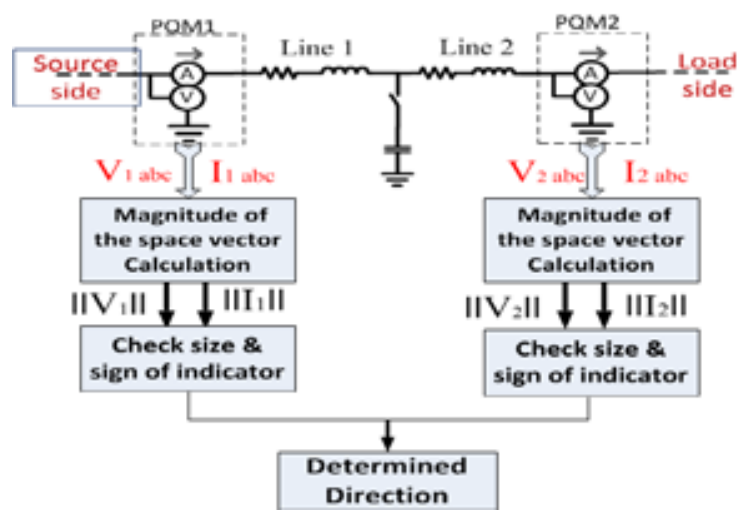

Fig. 7. Block-Diagram of the method based on the space vector of the current and voltage 
In this state, by calculating the index based on gradient of the transient voltage and current space vector $\left(I I D_{\mathrm{VI}} I\right)$, the direction of switching capacitor bank is determined using the following equation:

$$
\left\|\mathrm{D}_{\mathrm{VI}}\right\|=\left(\left\|\mathrm{V}\left(\mathrm{t}_{\mathrm{s}}^{+}\right)\right\|-\left\|\mathrm{V}\left(\mathrm{t}_{\mathrm{s}}^{-}\right)\right\|\right) \times\left(\left\|\mathrm{i}\left(\mathrm{t}_{\mathrm{s}}^{+}\right)\right\|-\left\|\mathrm{i}\left(\mathrm{t}_{\mathrm{s}}^{-}\right)\right\|\right)
$$

Where $\left(I I V\left(t_{s}^{-}\right) \|\right),\left(I I V\left(t_{s}^{+}\right) \|\right)$are the magnitude of the voltage space vector immediately before and after the switching instants and $\left(I \mathrm{Ii}\left(\mathrm{t}_{\mathrm{s}}^{-}\right) \|\right),\left(\left\|\mathrm{li}\left(\mathrm{t}_{\mathrm{s}}^{+}\right)\right\|\right)$are the magnitude of the current space vector immediately before and after switching instants.

Figs. 8, 9 show the space vectors of the current and voltage for the sample distribution network at two instants when crossing the voltage signal at peak $\left(\mathrm{t}_{\mathrm{s}=} 0.47\right)$ and crossing around zero $\left(\mathrm{t}_{\mathrm{s}}=0.283\right)$. According to Table 2, it can be seen that the index based on gradient of the transient voltage and current space vector $\left(I I D_{\mathrm{VI}} I\right)$, has correctly identified the direction of the switched capacitor bank in both states (a) and (b). Since all three-phase quantities contribute to the magnitude of the space vector and works with a quantity that represents contributions of the three-phase measured waveforms, this method is almost independent from the switching instant.

Figs. 8, 9 show the space vectors of the current and voltage for the sample distribution network at two instants when crossing the voltage signal at peak $\left(t_{s}=0.47\right)$ and crossing around zero $\left(t_{s}=0.283\right)$. According to Table 2, it can be seen that the index based on gradient of the transient voltage and current space vector (IID $\left.\mathrm{D}_{\mathrm{VI}} \mathrm{II}\right)$, has correctly identified the direction of the switched capacitor bank in both states (a) and (b). Since all three-phase quantities contribute to the magnitude of the space vector and works with a quantity that represents contributions of the three-phase measured waveforms, this method is almost independent from the switching instant.

\subsection{Switched Capacitor bank Direction Determination Represented by Flowchart}

After detection and classification the disturbance origin in the transient state, if the disturbance caused by the capacitor bank switching, extracting the transient current and voltage values measured

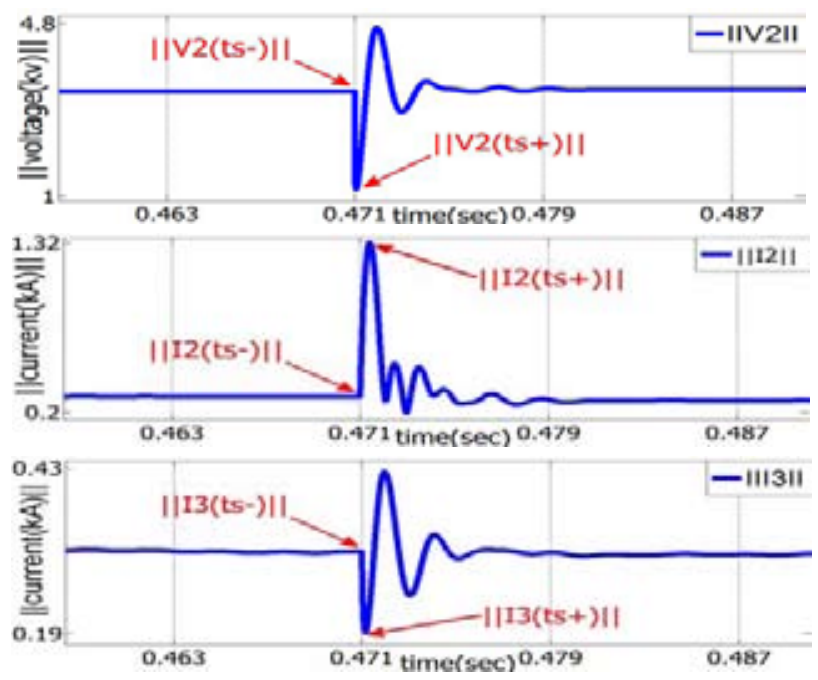

Fig. 8. Space vector of the current and voltage at the instant of crossing the signal at peak in the sample network (state(a)) 


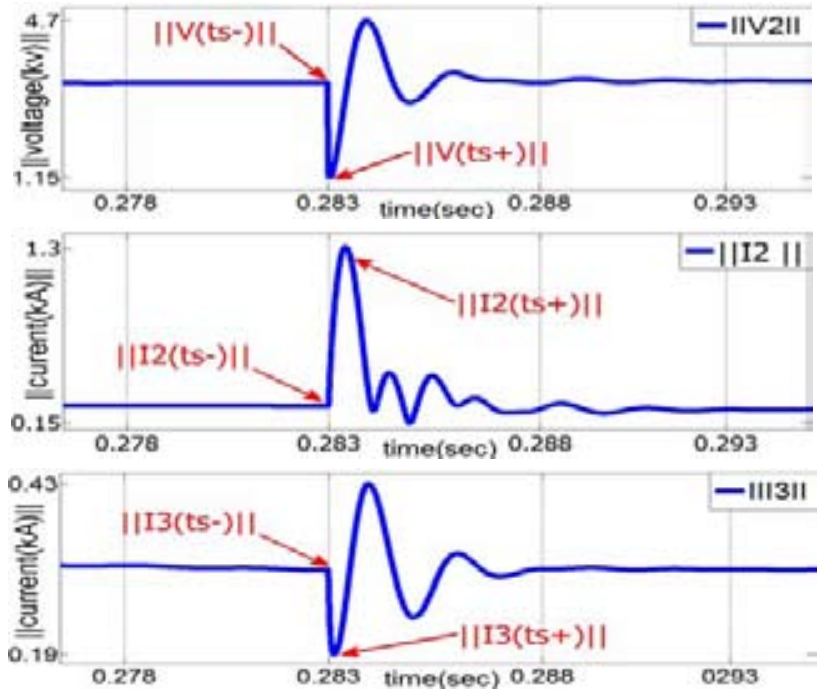

Fig. 9. Current and voltage Space vector magnitude at the instant of crossing the signal by around zero in the sample network (state (b))

Table 2. $\mathrm{D}_{\mathrm{VI}}$ index considering the space vector gradient of the current and voltage

\begin{tabular}{|c|c|c|c|c|}
\hline \multirow{2}{*}{ Branch } & \multicolumn{2}{|c|}{ state(a) } & \multicolumn{2}{c|}{ state(b) } \\
\cline { 2 - 5 } & $\boldsymbol{D}_{\boldsymbol{V}}$ & Sign & $\boldsymbol{D}_{\boldsymbol{V}}$ & Sign \\
\hline $\mathbf{1}$ & -2.14 & Negative & -2.115 & Negative \\
\hline $\mathbf{2}$ & -2.28 & Negative & -2.257 & Negative \\
\hline $\mathbf{3}$ & +0.25 & Posetive & +0.2457 & \multicolumn{2}{c}{} \\
\hline
\end{tabular}

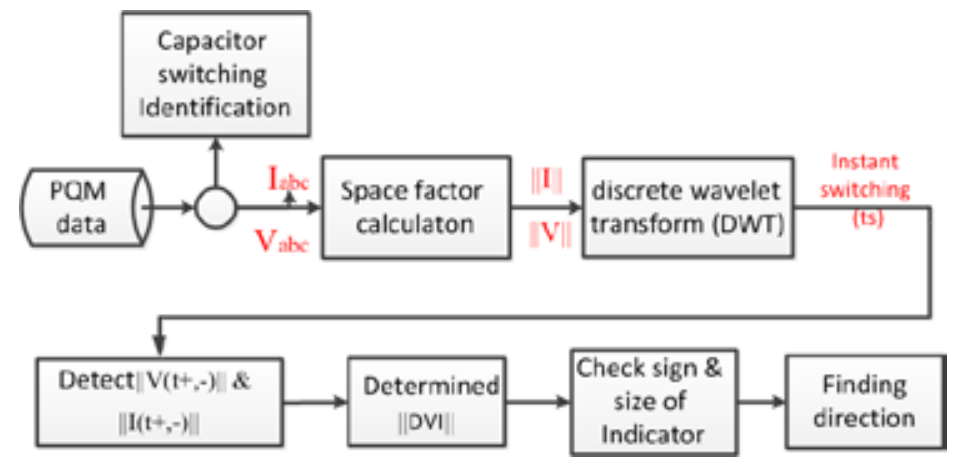

Fig. 10. The flowchart which represents the diagram direction finding for switched capacitor bank

by PQM and considering the method based on the space vector gradient, the indicator ${ }_{\mathrm{II}} \mathrm{D}_{\mathrm{VI}} \mathrm{Il}$ can be calculated. The following diagram represents the direction of switched capacitor bank determination in the real distribution system which is shown in Fig. 10. 


\section{Estimating the Distance between the Switching Capacitor Bank and the Monitoring Location}

After determining direction of the switched capacitor bank using the $I I \mathrm{D}_{\mathrm{VI}} \|$ index, if there is only one switching capacitor bank, it will not be necessary to estimate the distance, however, if in the desired branch, there are more than one switching capacitor banks estimating of the distance respect to the monitoring location in order to identify the disturbance origin is necessary. For example, the $\left\|\mathrm{D}_{\mathrm{VI}}\right\|$ index indicates that there is a switched capacitor located in the branch 2, but to determine which capacitor banks ( $\mathrm{C} 1$ or $\mathrm{C} 2)$ in the desired branch caused disturbance, the distance estimation can be efficient. Fig. 11 shows the sample distribution network with two switched capacitors where placed in the branch 2 .

Two approximately similar methods to estimate distance between the capacitor bank and the monitoring location are proposed in [6] and [10] using circuits theories and the initial changes of the voltage due to capacitor bank switching. The proposed method in [6] is introduced only for the category of capacitor banks that are placed at the downstream of the monitoring location and the distance estimation algorithm totally depends on switching instant so that the capacitor bank switching at each instant except for the time of crossing the voltage signal at peak, will result in many errors in distance estimation. In the represented algorithm in [10] which depending totally on the switching time, the effect of reactance laterals branches on estimating distance between the capacitor bank and the monitoring location ignored. In other words, in this method, generally, load inductance is considered very larger than thevenin and line inductances (more than 10 times), but if the number of system loads in the branch is large, since these loads are parallel, the inductance of equivalent load decreases intensely and the current from the same branch will be increased which can cause the error of distance estimation rises up to $40 \%$.

In this section, considering these two methods as well as application of changes in the magnitude of space vector of the current and voltage immediately after switching an efficient and novel technique to estimate distance between the capacitor bank and the monitoring location in a real distribution system will be introduced. Fig. 12 shows the equivalent circuit of the sample distribution network shown in Fig. 11.

In this section, toward estimating the capacitor bank distance considering the reactance effect on laterals in the each phase, the relations in the space vector domain is expressed.

It is assumed in this network that capacitor $\mathrm{C}_{1}$ is switched at the instant $) \mathrm{t}_{\mathrm{s}}($. It is noteworthy that due to switching of the capacitor $C_{1}$, the voltage at bus 3 immediately after switching $\left(V\left(t_{s}^{+}\right)\right)$, is not

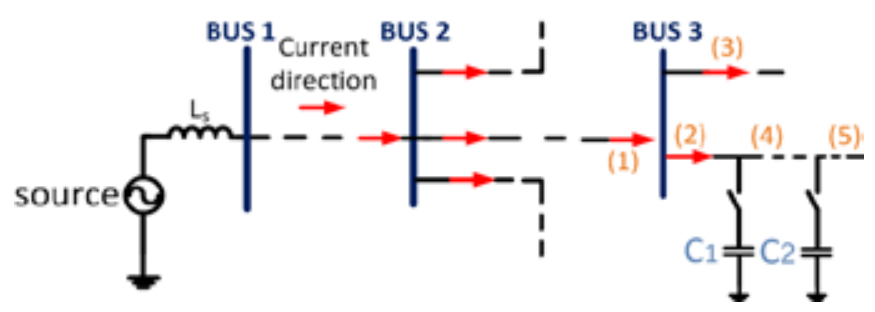

Fig. 11. The sample distribution system with two switching capacitors in the branch (2) 


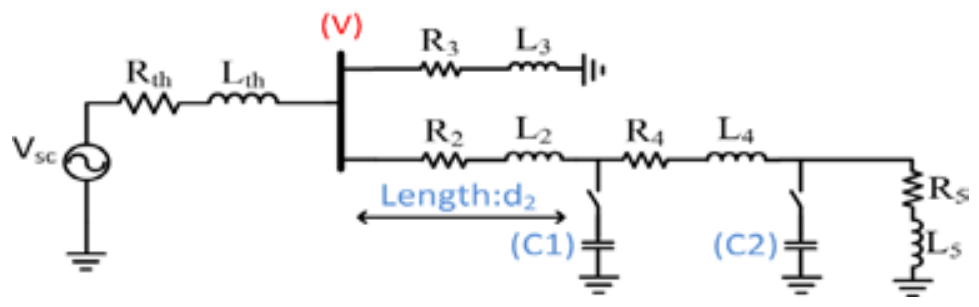

Fig. 12. Equivalent circuit of the distribution network shown in Fig. 11

dependent on parameters of the branches (4) and (5). Because the capacitor voltage at the switching instant is zero, therefore, all lines and downstream loads from the capacitor bank at the instant $\left(\mathrm{V}\left(\mathrm{t}_{\mathrm{s}}^{+}\right)\right)$ are ignored.

$\mathrm{V}_{\mathrm{SC}}\left(\mathrm{t}_{\mathrm{s}}{ }^{-}\right)$represents the system voltage before the switching instant which considered constant since the power system at fundamental frequency is substantially lower than a typical capacitor switching frequency. Voltage drop between $\mathrm{V}_{\mathrm{SC}}\left(\mathrm{t}_{\mathrm{s}}{ }^{-}\right)$and $\mathrm{V}\left(\mathrm{t}_{\mathrm{s}}{ }^{-}\right)$can be ignored therefore, in (9), $\mathrm{V}\left(\mathrm{t}_{\mathrm{s}}{ }^{-}\right)$can be replaced by $\mathrm{V}_{\mathrm{SC}}\left(\mathrm{t}_{\mathrm{s}}{ }^{-}\right)$, therefore:

$$
\begin{aligned}
& L_{e q}=\frac{L_{2} L_{3}}{L_{2}+L_{3}} \\
& V\left(t_{s}^{+}\right)=\frac{L_{e q}}{L_{e q}+L_{t h}} \times V_{s c}\left(t_{s}^{-}\right) \Rightarrow V\left(t_{s}^{+}\right)=\frac{L_{e q}}{L_{e q}+L_{t h}} \times V\left(t_{s}^{-}\right) \\
& L_{e q}=\frac{V\left(t_{s}^{+}\right)}{V\left(t_{s}^{-}\right)-V\left(t_{s}^{+}\right)} \times L_{t h} \\
& \Rightarrow L_{e q}=K \times L_{t h}
\end{aligned}
$$

Considering (9), (12) $\mathrm{L}_{2}$ can be obtained from the following equation:

$$
\Rightarrow L_{2}=K \frac{L_{t h} L_{3}}{L_{3}+L_{t h}}
$$

On the other hand, since at the instant $\left(\mathrm{t}_{\mathrm{s}}{ }^{+}\right)$the branches 2 and 3 are parallel, the following relation can be written:

$$
\begin{aligned}
& L_{2} \frac{d i_{2}\left(t_{s}^{+}\right)}{d t}=L_{3} \frac{d i_{3}\left(t_{s}^{+}\right)}{d t} \\
& \Rightarrow \frac{L_{2}}{L_{3}}=\frac{d i_{3}\left(t_{s}^{+}\right)}{d i_{2}\left(t_{s}^{+}\right)}=\frac{i_{3}\left(t_{s}^{\prime+}\right)-i_{3}\left(t_{s}^{+}\right)}{i_{2}\left(t_{s}^{\prime+}\right)-i_{2}\left(t_{s}^{+}\right)}=\psi \\
& \left\{\begin{array}{l}
L_{2}=K \frac{L_{t h} \cdot L_{3}}{L_{3}-K L_{t h}} \\
\frac{L_{2}}{L_{3}}=\psi
\end{array}\right.
\end{aligned}
$$




$$
L_{2}=d_{2} \times L_{u} \Rightarrow d_{2}=K \times \frac{L_{t h}}{L_{u}}(1+\psi)
$$

where $i_{2}\left(t_{s}^{+}\right), i_{3}\left(t_{s}^{+}\right)$represent respectively the current value of the branch (2) and (3) immediately after the instant $\left(\mathrm{t}_{\mathrm{s}}\right), \mathrm{i}_{2}\left(\mathrm{t}_{\mathrm{s}}{ }^{+}\right)$and $\mathrm{i}_{3}\left(\mathrm{t}_{\mathrm{s}}{ }^{+}\right)$represent respectively the current value of the branch (2) and (3) immediately after the instant $\left(t_{s}^{+}\right)$and $(\psi)$ is introduced as the ratio of the changes in the current of the branch 3 to the changes in the current of the branch 2 .

In relation (16), $\mathrm{L}_{\mathrm{U}}$ is the inductance per-unit length of line and calculated based on the system specifications. $\mathrm{V}\left(\mathrm{t}_{\mathrm{S}}{ }^{+}\right)$and $\mathrm{V}\left(\mathrm{t}_{\mathrm{S}}{ }^{-}\right)$values are calculated based on the transient voltage waveforms and $\mathrm{d}_{2}$ represents the distance between the switched capacitor bank and the monitoring location. Thevenin inductance $\left(\mathrm{L}_{\text {th }}\right)$ can be calculated by short $\%$ - circuit current in the monitoring location or considering only the inductance of the main feeder from the monitoring location to the source without considering laterals. If the monitoring location is not far from the source, this simplification does not make a significant error.

If according to Fig. 13, there are the (n) branches in the monitoring location (bus 3), the distance between the switched capacitor bank and the monitoring location $\left(\mathrm{d}_{2}\right)$ is calculated by relation (17).

$$
d_{2}=K \frac{L_{t h}}{L_{u}}\left(1+\Psi_{1}+\ldots+\Psi_{n}\right) \Rightarrow \Psi_{n}=\frac{i_{n}\left(t_{s}^{\prime+}\right)-i_{n}\left(t_{s}^{+}\right)}{i_{2}\left(t_{s}^{+1}\right)-i_{2}\left(t_{s}^{+}\right)}
$$

In (17), taking into account the reactance of laterals, provides an estimation of the switched capacitor bank distance in each phase. Due to the phase difference, the voltage of each phase at the switching instant is in a different situation and because parameter $(\mathrm{K})$ depends on voltage value immediately before and after switching instant, parameter $(\mathrm{K})$ in each phase is different from two other phases which can results in estimating three distances from monitoring location so that except for capacitor bank switching right at the moment when voltage crossing at the peak, none of them will be near to reality.

As capacitor bank switching may occur at every moment (including switching at peak, zero crossing or between them) and distance estimation in the method based on the each phase, is totally dependence on the switching instant, the method based on the space vector is presented to estimate the switching capacitor bank distance from the monitoring location and the distance estimation is not only independent from the switching instant, but also is calculated one unit for three phases $\mathrm{K}\left(\mathrm{K}_{\mathrm{s.v}}\right)$ which includes the information of three phases.

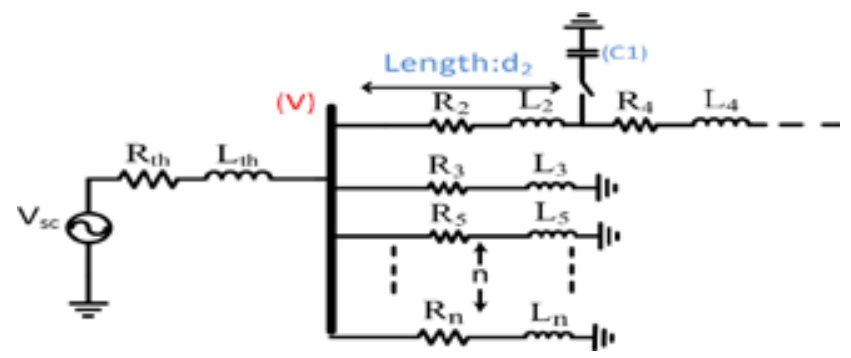

Fig. 13. The sample distribution network with (n) branches in the monitoring location 
(18) to (32) represent how to estimate capacitor banks distance considering inductance laterals in the space vector domain.

Regarding (10), it can be written:

$$
\begin{aligned}
& \left\{\begin{array}{l}
V_{a}\left(t_{s}^{+}\right)=\frac{L_{e q}}{L_{t h}+L_{e q}} V_{a}\left(t_{s}^{-}\right) \\
V_{b}\left(t_{s}^{+}\right)=\frac{L_{e q}}{L_{t h}+L_{e q}} V_{b}\left(t_{s}^{-}\right) \Rightarrow\left[\begin{array}{c}
V_{a}\left(t_{s}^{+}\right) \\
V_{b}\left(t_{s}^{+}\right) \\
V_{c}\left(t_{s}^{+}\right)
\end{array}\right]=\frac{L_{e q}}{L_{t h}+L_{e q}}\left[\begin{array}{c}
V_{a}\left(t_{s}^{-}\right) \\
V_{b}\left(t_{s}^{-}\right) \\
V_{c}\left(t_{s}^{-}\right)
\end{array}\right] \\
V_{c}\left(t_{s}^{+}\right)=\frac{L_{e q}}{L_{t h}+L_{e q}} V_{c}\left(t_{s}^{-}\right)
\end{array}\right. \\
& K V_{a b c}\left(t_{s}^{+}\right)=\frac{L_{e q}}{L_{e q}+L_{t h}} K V_{a b c}\left(t_{s}^{-}\right) \Rightarrow V_{d q o}\left(t_{s}^{+}\right)=\frac{L_{e q}}{L_{e q}+L_{t h}} V_{d q o}\left(t_{s}^{-}\right)
\end{aligned}
$$

In such state, according to (7), voltage magnitude can be obtained by the following equation:

$$
\left\{\begin{array}{l}
\left\|V\left(t_{s}^{+}\right)\right\|=\sqrt{\left(V_{d}\left(t_{s}^{+}\right)\right)^{2}+\left(V_{q}\left(t_{s}^{+}\right)\right)^{2}+\left(V_{o}\left(t_{s}^{+}\right)\right)^{2}} \\
\left\|V\left(t_{s}^{-}\right)\right\|=\sqrt{\left(V_{d}\left(t_{s}^{-}\right)\right)^{2}+\left(V_{q}\left(t_{s}^{-}\right)\right)^{2}+\left(V_{o}\left(t_{s}^{-}\right)\right)^{2}}
\end{array}\right.
$$

According to (20), the magnitude of the space vector after switching instant of the capacitor bank in frame ( dqo) can be written similar to (21) and the equivalent inductance of branches (2) and (3) can be calculated based on the magnitude of the space vector of the voltage before and after switching instant.

$$
\begin{aligned}
& \left\|V\left(t_{s}^{+}\right)\right\|=\frac{L_{e q}}{L_{t h}+L_{e q}}\left\|V\left(t_{s}^{-}\right)\right\| \Rightarrow L_{e q}=\frac{\left\|V\left(t_{s}^{+}\right)\right\|}{\left\|V\left(t_{s}^{-}\right)\right\|-\left\|V\left(t_{s}^{+}\right)\right\|} \times L_{t h} \\
& K_{s . v}=\frac{\left\|V\left(t_{s}^{+}\right)\right\|}{\left\|V\left(t_{s}^{-}\right)\right\|-\left\|V\left(t_{s}^{+}\right)\right\|} \Rightarrow L_{e q}=K_{s . v} \times L_{t h}
\end{aligned}
$$

Regarding (9) and (22), $\mathrm{L}_{2}$ can be derived as follows:

$$
\Rightarrow L_{2}=k_{s, v} \frac{L_{t h} L_{3}}{L_{3}+L_{t h}}
$$

Considering (14), as branches (2) and (3) are parallel, it can be written at the instant $\left(\mathrm{t}_{\mathrm{s}}^{+}\right)$:

$$
V_{a b c}\left(t_{s}^{+}\right)=L_{2} \frac{d i_{2 a b c}\left(t_{s}^{+}\right)}{d t}=L_{3} \frac{d i_{3 a b c}\left(t_{s}^{+}\right)}{d t}
$$

Similar to (19), by transferring from triaxial apparatus (abc) to the frame (dqo), the voltage in the frame (dqo) is introduced as follows:

$$
\left\{\begin{array}{l}
\left(V_{a b c}\left(t_{s}^{+}\right)=L_{2} \frac{d i_{2 a b c}\left(t_{s}^{+}\right)}{d t}\right) \times K \\
\left(V_{a b c}\left(t_{s}^{+}\right)=L_{3} \frac{d i_{3 a b c}\left(t_{s}^{+}\right)}{d t}\right) \times K
\end{array}\right.
$$




$$
\Rightarrow\left\{\begin{array}{l}
V_{q d o}\left(t_{s}^{+}\right)=K L_{2} K^{-1} i_{d q o_{2}}\left(t_{s}^{+}\right)+K L_{2} K^{-1} \frac{d i_{d q o_{2}}\left(t_{s}^{+}\right)}{d t} \\
V_{q d o}\left(t_{s}^{+}\right)=K L_{3} K^{{ }^{-1}} i_{d q o 3}\left(t_{s}^{+}\right)+K L_{3} K^{-1} \frac{d i_{d q o_{3}}\left(t_{s}^{+}\right)}{d t}
\end{array}\right.
$$

On the other hand, it can be simplified as follows:

$$
K L K^{\prime-1}=\omega\left[\begin{array}{ccc}
0 & 1 & 0 \\
-1 & 0 & 0 \\
0 & 0 & 0
\end{array}\right]\left[\begin{array}{c}
i_{q} \\
i_{d} \\
i_{0}
\end{array}\right], K L K^{-1}=L
$$

In (25), K.L.K ${ }^{\prime-1} \cdot \mathrm{i}_{\mathrm{dq}}$ is called voltage motion parameter which is circulating with speed $\left(\omega_{e}\right)$ under the system nominal frequency $\left(\mathrm{f}_{\mathrm{sys}}=60(\mathrm{~Hz})\right)$ and $\left(K . L . K^{-1} d i_{d q o} / d t\right)$ is the transient state voltage of the system which is considered with speed $\left(\omega_{d}\right)$. Switching frequency of the capacitor bank is in the range (300-1000) hertz [7], therefore signal frequency in the transient state is also in the same range. In this state, approximately, the ratio $\left(\omega_{e} / \omega_{d}\right)$ is almost between 5 to 15 . In this condition, the voltage motion parameter K.L.K ${ }^{\prime-1} . i_{\mathrm{dq}}$ versus the transient state voltage of the system $K . L . K^{-1} d i_{d q o} / d t$ can be ignored. Therefore, according to the above mentioned discussions, voltage equation in the monitoring location in the reference frame (dqo) is introduced as (27).

$$
\begin{aligned}
& V_{q d o}\left(t_{s}^{+}\right)=L_{2} \frac{d i_{d q o_{2}}\left(t_{s}^{+}\right)}{d t}=L_{3} \frac{d i_{d q o_{3}}\left(t_{s}^{+}\right)}{d t} \\
& \|V\|=L_{2}\left\|\frac{d i_{2}\left(t_{s}^{+}\right)}{d t}\right\|=L_{3}\left\|\frac{d i_{3}\left(t_{s}^{+}\right)}{d t}\right\| \\
& \frac{L_{2}}{L_{3}}=\left\|\frac{d i_{3}\left(t_{s}^{+}\right)}{d i_{2}\left(t_{s}^{+}\right)}\right\|=\left\|\frac{i_{3}\left(t_{s}^{\prime+}\right)-i_{3}\left(t_{s}^{+}\right)}{d i_{2}\left(t_{s}^{\prime+}\right)-d i_{2}\left(t_{s}^{+}\right)}\right\|=\Psi_{s . v}
\end{aligned}
$$

In (29), $\left\|i_{3}\left(t^{\prime}{ }^{+}\right)\right\|$is the magnitude of the current space vector of branch (3) immediately after switching instant $\left(\mathrm{t}_{\mathrm{s}}^{+}\right)$and $\mathrm{Ii}_{2}\left(\mathrm{t}_{\mathrm{s}}{ }^{+}\right) \|$is the magnitude of the current space vector of branch (2) immediately after switching at the instant $\left(t_{\mathrm{s}}^{+}\right)$. The parameter $\left(\Psi_{\mathrm{s} . \mathrm{v}}\right)$ is defined as ratio of changes in the magnitude of the current space vector of branch (3) to changes in the magnitude of the current space vector of branch (2) after capacitor bank switching.

Regarding (23) and (29), the inductance of branch (2) is written based on changes in the magnitude of the voltage space vector before and after switching, the ratio of changes in the magnitude of the current space vector of branches (2) and (3) and thevenin inductance.

$$
L_{2}=K_{s, v} L_{t h}\left(1+\Psi_{s, v}\right)
$$

On the other hand, the inductance of branch (2) can be written as follows:

$$
L_{2}=d_{2} \times L_{u} \Rightarrow d_{2}=K_{s, v} \times \frac{L_{t h}}{L_{u}}\left(1+\Psi_{s, v}\right)
$$

In this case, the distance of switched capacitor bank from the monitoring location in the domain of space vector is estimated by (31). Similar to (17), to generalize to derived an equation in the space 
domain, according to the Fig. 13, if there are the (n) branches in the monitoring location, the distance between the switched capacitor bank and the monitoring location $\left(\mathrm{d}_{2}\right)$ is calculated based on relation (32).

$$
d_{2}=K_{s, v} \times \frac{L_{t h}}{L_{u}}\left(1+\Psi_{s, v_{1}}+\Psi_{s, v_{2}}+\ldots+\Psi_{s, v_{n}}\right)
$$

\section{Simulation Result}

In this section, effectiveness and applicability of the method in finding direction and estimating the distance of the switched capacitor bank in different situations (normal and Back-To-Back), in the presence of stochastic nonlinear loads and change of sampling rate in IEEE-13 Bus system are studied by PSCAD. The specifications of this network (Fig. 14) were reported in [12].

\subsection{Capacitor bank switching in the normal state \\ (except back-to-back condition)}

In this system, a 300-kVAr three-phase capacitor bank located on bus 633 is switched on and the distance between the switching capacitor bank (bus 633) and the monitoring location (bus 632) is considered 0.1 mile in simulations (Fig. 15). In this case, suppose that the fixed capacitor does not exist in any other buses. In order to monitor all branches, P.Q.M.s are located on buses 632 and 671. Table 3 show the indicator of the space vector of the current and voltage ( $\left.\mathrm{IID}_{\mathrm{VI}} \mathrm{II}\right)$ for all branches to find direction the switched capacitor bank. Table 4 indicates the distance between the switched capacitor bank and the monitoring location in the desired branch.

Regarding the flowchart of finding direction of capacitor bank based on gradient of the transient voltage and current space vector (3-c), since the switched capacitor bank in the system under study is in branch (2), therefore the polarity of the indicator of the space vector ( $\left(I \mathrm{D}_{\mathrm{VI}} I\right)$ for the branches (1) and (2) is negative and it is positive in other branches. Moreover, the value of indicator $\mathrm{IID}_{\mathrm{VI}} \mathrm{ll}$ in branch (2) is larger than the indicator $I I D_{\mathrm{VI}} \|$ in other branches (here, branch 1). The results of Table 3 shows the above mentioned issues.

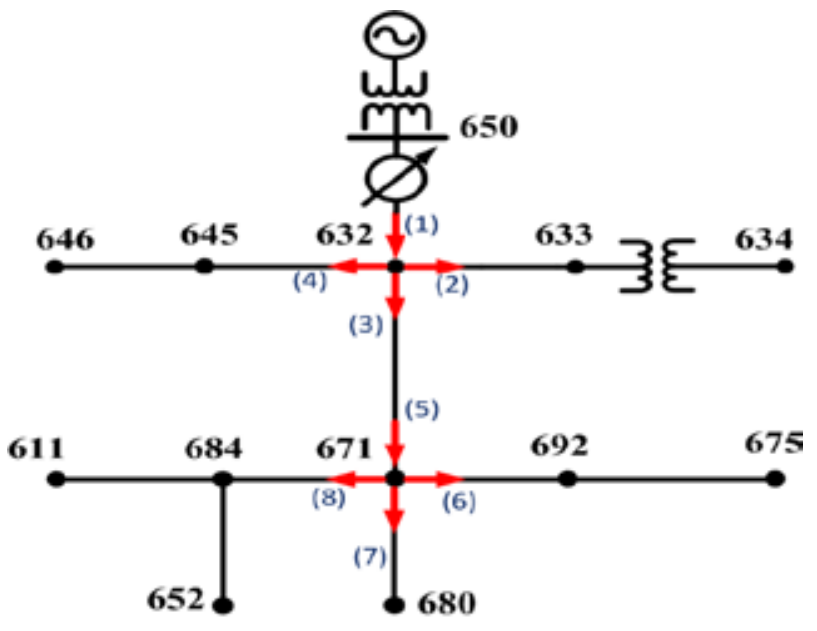

Fig. 14. IEEE-13 Bus Distribution network 


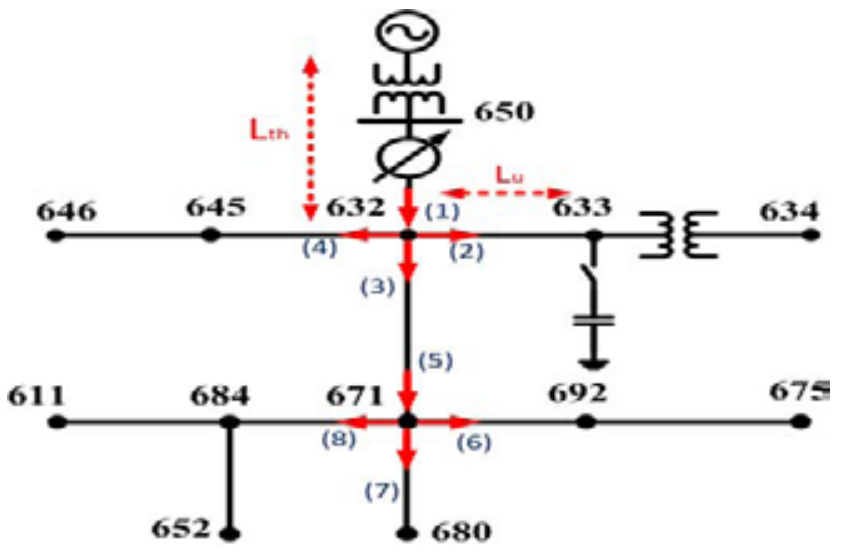

Fig. 15. Capacitor bank switching at bus 633 in normal switching state

Table 3. Determining direction of the switched capacitor bank at bus 633 by IID $_{\mathrm{VI}} \mathrm{II}$ in normal switching state

\begin{tabular}{|c|c|c|c|}
\hline Branch & $\left\|\mathrm{V}\left(\mathrm{t}_{\mathrm{s}}^{-}\right)\right\|,\left\|\mathrm{V}\left(\mathrm{t}_{\mathrm{s}}^{+}\right)\right\|$ & $\left\|\mathrm{I}\left(\mathrm{t}_{\mathrm{s}}^{-}\right)\right\|,\left\|\mathrm{I}\left(\mathrm{t}_{\mathrm{s}}^{+}\right)\right\|$ & $\left\|\mathrm{D}_{\mathrm{VI}}\right\|$ \\
\hline 1 & $(3.4663,1.1947)$ & $(0.7610,0.9818)$ & -0.4993 \\
\hline 2 & $(3.4663,1.1947)$ & $(0.0836,0.5875)$ & -1.1260 \\
\hline 3 & $(3.4663,1.1947)$ & $(0.6582,0.5150)$ & +0.3199 \\
\hline 4 & $(3.4663,1.1947)$ & $(0.2053,0.0936)$ & +0.2496 \\
\hline 5 & $(3.4986,1.1804)$ & $(0.4678,0.3719)$ & +0.1468 \\
\hline 6 & $(3.4986,1.1804)$ & $(0.1837,0.1742)$ & +0.0145 \\
\hline 7 & $(3.4986,1.1804)$ & $(0,0)$ & +0.022 \\
\hline 8 & $(3.4986,1.1804)$ & $(0.0299,0.0154)$ & -- \\
\hline 9 & $(3.4986,1.1804)$ & $(0,0)$ & \\
\hline
\end{tabular}

Regarding the technique proposed in section 4, the exact location of the switched capacitor bank is determined by the magnitude of the space vector of the transient voltage and current. $\mathrm{L}_{u}$ is the inductance per-unit length of line (2), which assumed to be known. The inductance of the main feeder from the monitoring location at bus 632 to the source (branch (1)), is considered as $\mathrm{L}_{\mathrm{th}}$. Parameters $\mathrm{L}_{\mathrm{u}}$ and $\mathrm{L}_{\text {th }}$ are calculated based on the specification of network IEEE-13 bus [12]. It can be seen in Table 4 , the error of distance estimation is $7.3 \%$ approximately.

As shown in Fig. 16, if the switching capacitor bank is removed from bus 633 and placed in 0.15 mile from monitoring location on the bus 671 (the distance between buses 692,675 is considered 0.15 mile). In this case, Tables 5 and 6 show simulation results for the calculation of IID $_{\mathrm{VI}} \mathrm{II}$ and estimated distance of the switched capacitor bank from the monitoring location in normal switching state respectively.

In Fig. 16, since the switched capacitor bank in the system under study is in branch (6), therefore the polarity of the indicator of the space vector (IID $\mathrm{VII}_{\mathrm{VI}}$ ) for the branches (1), (3), (5) and (6) should be negative and positive in other branches. Moreover, the value of indicator $\mathrm{IID}_{\mathrm{VI}} \mathrm{II}$ in branch (6) is larger 
Table 4. Estimating the distance between the switched capacitor bank at bus 633 and the monitoring location at bus 632 in normal switching state

\begin{tabular}{|c|c|c|c|c|c|c|}
\hline Error & $\mathrm{D}_{\text {real }}$ & $\mathrm{D}_{\mathrm{est}}$ & $\Psi_{2}$ & $\Psi_{1}$ & $\mathrm{~K}_{\mathrm{S} . \mathrm{V}}$ & $\|\left(\mathrm{V}\left(\mathrm{t}_{\mathrm{S}}{ }^{-}, \mathrm{t}_{\mathrm{S}}{ }^{+}\right) \|\right.$ \\
\hline $7.3 \%$ & 0.1 & 0.1071 & -0.028 & -0.201 & 0.52 & $(3.466,1.1947)$ \\
\hline
\end{tabular}

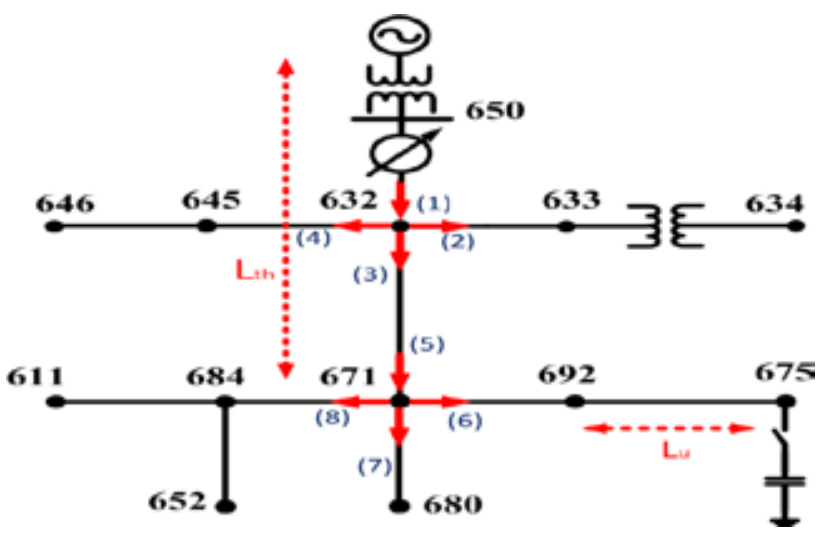

Fig. 16. Capacitor bank switching at bus 675 in normal switching state

Table 5. Determining direction of the switched capacitor bank at bus 675 by IID $_{\mathrm{VI}} \mathrm{II}$ in normal switching state

\begin{tabular}{|c|c|c|c|}
\hline Branch & $\left\|\mathrm{V}\left(\mathrm{t}_{\mathrm{s}}^{-}\right)\right\|,\left\|\mathrm{I}\left(\mathrm{t}_{\mathrm{s}}{ }^{+}\right)\right\|$ & $\left\|\mathrm{II}\left(\mathrm{t}_{\mathrm{s}}^{-}\right)\right\|,\left\|\mathrm{I}\left(\mathrm{t}_{\mathrm{s}}^{+}\right)\right\|$ & $\left\|\mathrm{D}_{\mathrm{VI}}\right\|$ \\
\hline 1 & $(3.4663,2.3486)$ & $(0.7610,0.7972)$ & -0.0404 \\
\hline 2 & $(3.4663,2.3486)$ & $(0.0836,0.0751)$ & $+9.5 \mathrm{E}-3$ \\
\hline 3 & $(3.4663,2.3486)$ & $(0.6583,0.7478)$ & -0.1 \\
\hline 4 & $(3.4663,2.3486)$ & $(0.2053,0.1621)$ & +0.0482 \\
\hline 5 & $(3.3917,0.61)$ & $(0.4678,0.561)$ & -0.2592 \\
\hline 6 & $(3.3917,0.61)$ & $(0.1837,0.4895)$ & -0.8506 \\
\hline 7 & $(3.3917,0.61)$ & $(0,0)$ & --- \\
\hline 8 & $(3.3917,0.61)$ & $(0.0308,0.02588)$ & +0.0136 \\
\hline 9 & $(3.3917,0.61)$ & $(0,0)$ & --- \\
\hline
\end{tabular}

Table 6. Estimating the distance between the switched capacitor bank at bus 675 and the monitoring location at bus 671 in normal switching state

\begin{tabular}{|c|c|c|c|c|c|c|}
\hline Error & $\mathrm{D}_{\text {real }}$ & $\mathrm{D}_{\text {est }}$ & $\Psi_{2}$ & $\Psi_{1}$ & $\mathrm{~K}_{\mathrm{S} . \mathrm{V}}$ & $\|\left(V\left(t_{S^{-}}, t_{S}^{+}\right) \|\right.$ \\
\hline $8.1 \%$ & 0.15 & 0.1621 & 0 & -0.35 & 0.22 & $(3.3917,0.61)$ \\
\hline
\end{tabular}


than the indicator IID $_{\mathrm{VI}} \mathrm{II}$ in other branches (here, branches $1,3,5$ ). The results in Table 5 satisfies the above mentioned expectations.

Table 5 shows the estimate distance of switched capacitor bank based on magnitude of space vector voltage and current transients at bus 675 .

From the Tables 5 and 6, it can be seen that under the normal capacitor bank switching at various locations, determining direction and estimating the distance between the switched capacitor bank and the monitoring location have been, properly done.

\subsection{Capacitor bank switching}

in the back-to-back switching state

Switching of capacitor bank, in the presence of the fixed capacitor bank, known as back-to-back switching in the studied network. The initial inrush currents of the capacitors which were successively connected in a back-to-back scenario were limited by using series inductors with impedances typically less than $1 \%$ of the capacitors reactance. In the back-to-back state, because of resonance between the limiter inductor and capacitors, the frequency of the transient state increases compared to the normal switching state; In the normal switching, such transient states in high frequency are not created, due to the higher inductance of the network in the instant of switching.

To study algorithm in the back-to-back switching conditions, In the first case, as shown in Fig. 17, the capacitor bank placed in bus 633 in presence of a fixed capacitor bank, 200-kVAr three-phases located in bus 692 is switched on and In the next case which is represented in Fig. 18, the capacitor bank placed in bus 675 in presence of a fixed capacitor bank, 200-kVAr three-phases mounted in bus 633 is switched on. Tables 7, 9 shows the index from the space vector of the transient current and voltage (IID $\left.\mathrm{DVI}_{\mathrm{VI}} \mathrm{I}\right)$ to find direction the switching the capacitor bank and Table 8, 10 indicates the results of estimating the distance between the switched capacitor bank and the monitoring location in the mentioned branches.

The results represented in Tables 7, 9 show that back-to-back switching can affect only the values of indices compared to normal switching and not the method accuracy. It can be seen in Tables 8 , 10 that the error of estimating the distance in the back-to-back switching increased compared to the normal switching. The proposed method in different conditions (normal and back-to-back) were studied

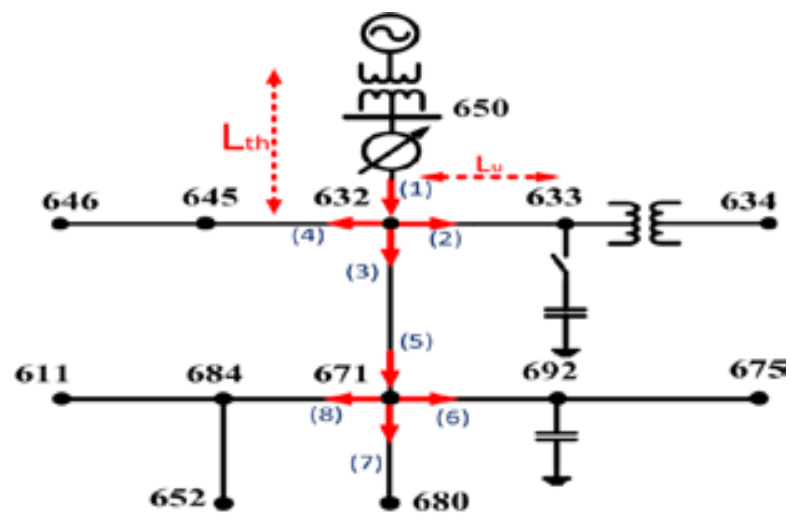

Fig. 17. Capacitor bank switching at bus 633 in the Back-To-Back switching state 


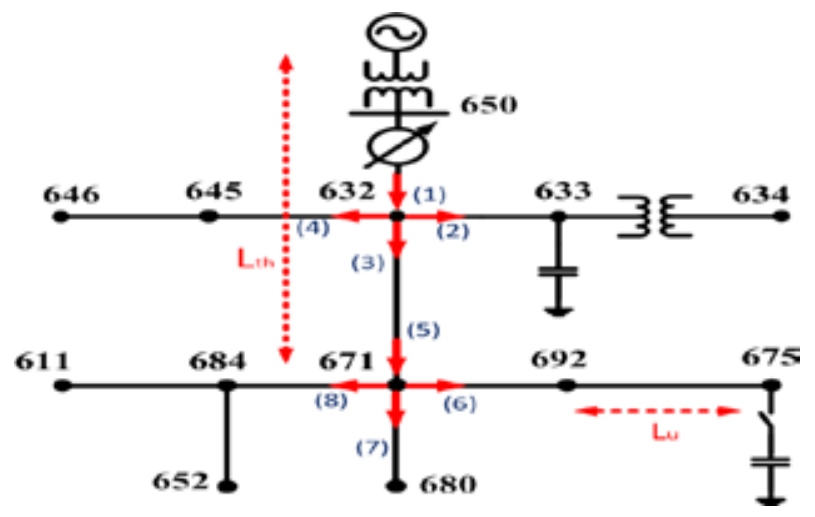

Fig. 18. Capacitor bank switching at bus 675 in the Back-To-Back switching state

Table 7. Determining direction of the switched capacitor bank at bus 633 using IID $_{\mathrm{VI}} \mathrm{II}$ in Back-To-Back switching state

\begin{tabular}{|c|c|c|c|}
\hline Branch & IIV( $\left.\mathrm{t}_{\mathrm{s}}^{-}\right) \mathrm{II}, \mathrm{IIV}\left(\mathrm{t}_{\mathrm{s}}^{+}\right) \mathrm{II}$ & $\mathrm{III}\left(\mathrm{t}_{\mathrm{s}}^{-}\right) \mathrm{II}, \mathrm{III}\left(\mathrm{t}_{\mathrm{s}}^{+}\right) \mathrm{II}$ & $\left\|\mathrm{D}_{\mathrm{VI}}\right\|$ \\
\hline 1 & $(3.4964,1.4459)$ & $(0.6882,0.8240)$ & -0.2784 \\
\hline 2 & $(3.4964,1.4459)$ & $(0.0829,0.4650)$ & -0.7834 \\
\hline 3 & $(3.4964,1.4459)$ & $(0.4461,0.3147)$ & +0.2694 \\
\hline 4 & $(3.4964,1.4459)$ & $(0.1645,0.0885)$ & +0.1558 \\
\hline 5 & $(3.4525,3.4119)$ & $(0.3878,0.2679)$ & $+4.86 \mathrm{E}-3$ \\
\hline 6 & $(3.4525,3.4119)$ & $(0.1040,0.0646)$ & $+1.59 \mathrm{E}-3$ \\
\hline 7 & $(3.4525,3.4119)$ & $(0,0)$ & +- \\
\hline 8 & $(3.4525,3.4119)$ & $(0.0289,0.0268)$ & $+8.52 \mathrm{E}-5$ \\
\hline 9 & $(3.4525,3.4119)$ & $(0,0)$ & --- \\
\hline
\end{tabular}

Table 8. Estimating the distance between the switched capacitor bank at bus 633 and the monitoring location at bus 632 in Back-To-Back switching

\begin{tabular}{|c|c|c|c|c|c|c|}
\hline Error & $\mathrm{D}_{\text {real }}$ & $\mathrm{D}_{\text {est }}$ & $\Psi_{2}$ & $\Psi_{1}$ & $\mathrm{~K}_{\mathrm{S} . \mathrm{V}}$ & $\|\left(V\left(t_{S}{ }^{-}, t_{S}^{+}\right) \|\right.$ \\
\hline $12.1 \%$ & 0.1 & 0.1121 & -0.047 & -0.36 & 0.705 & $(3.496,1.4459)$ \\
\hline
\end{tabular}

under different situations such as changes in the size and location of the switched capacitor bank and simulation results verified the effectiveness of the proposed algorithm.

\subsection{Capacitor bank switching in presence of stochastic nonlinear load}

Regarding the fact that the transient states of the systems with capacitors could have unpredicTable behavior in the presence of stochastic nonlinear loads and affect the analysis in the proposed algorithm, in this section, in addition to PQ loads with nonlinear nature, the proposed algorithm will be tested by adding a three-phase electric arc furnace with power of $0.65 \mathrm{MVA}$, in bus 
Table 9. Determining direction of the switched capacitor bank at bus 675 using IID $_{\mathrm{VI}} \mathrm{II}$ in Back-To-Back switching

\begin{tabular}{|c|c|c|c|}
\hline Branch & IIV(t $\left.{ }_{\mathrm{s}}^{-}\right) \mathrm{II}, \mathrm{IIV}\left(\mathrm{t}_{\mathrm{s}}^{+}\right) \mathrm{II}$ & $\mathrm{III}\left(\mathrm{t}_{\mathrm{s}}^{-}\right) \mathrm{II}, \mathrm{III}\left(\mathrm{t}_{\mathrm{s}}^{+}\right) \mathrm{II}$ & $\left\|\mathrm{D}_{\mathrm{VI}}\right\|$ \\
\hline 1 & $(3.4078,2.9103)$ & $(0.6889,0.7053)$ & $-8.159 \mathrm{E}-3$ \\
\hline 2 & $(3.4078,2.9103)$ & $(0.0958,0.0678)$ & +0.0139 \\
\hline 3 & $(3.4078,2.9103)$ & $(0.5223,0.5996)$ & -0.0384 \\
\hline 4 & $(3.4078,2.9103)$ & $(0.1646,0.1489)$ & $+7.81 \mathrm{E}-4$ \\
\hline 5 & $(3.4217,0.6508)$ & $(0.4640,0.5442)$ & -0.2222 \\
\hline 6 & $(3.4217,0.6508)$ & $(0.1827,0.4781)$ & -0.8185 \\
\hline 7 & $(3.4217,0.6508)$ & $(0,0)$ & --- \\
\hline 8 & $(3.4217,0.6508)$ & $(0.0302,0.02513)$ & +0.01402 \\
\hline 9 & $(3.4217,0.6508)$ & $(0,0)$ & -- \\
\hline
\end{tabular}

Table 10. Estimating the distance between the switched capacitor bank at bus 675 and the monitoring location at bus 671 in Back-To-Back switching state

\begin{tabular}{|c|c|c|c|c|c|c|}
\hline Error & $\mathrm{D}_{\text {real }}$ & $\mathbf{D}_{\text {est }}$ & $\Psi_{2}$ & $\Psi_{1}$ & $\mathrm{~K}_{\mathrm{S} . \mathrm{V}}$ & $\|\left(\mathrm{V}\left(\mathrm{t}_{\mathrm{s}}{ }^{-}, \mathrm{t}_{\mathrm{S}}{ }^{+}\right) \|\right.$ \\
\hline $15.6 \%$ & 0.15 & 0.1725 & 0 & -0.28 & 0.234 & $(3.4217,0.650)$ \\
\hline
\end{tabular}

Table 11. Determining direction of the capacitor bank using $\mathrm{IID}_{\mathrm{VI}} \mathrm{II}$ in the presence of stochastic nonliner loads in the normal switching state

\begin{tabular}{|c|c|c|c|}
\hline Branch & IIV( $\left.\mathrm{t}_{\mathrm{s}}^{-}\right) \mathrm{II}, \mathrm{IIV}\left(\mathrm{t}_{\mathrm{s}}^{+}\right) \mathrm{II}$ & $\mathrm{III}\left(\mathrm{t}_{\mathrm{s}}^{-}\right) \mathrm{II}, \mathrm{III}\left(\mathrm{t}_{\mathrm{s}}^{+}\right) \mathrm{II}$ & $\left\|\mathrm{D}_{\mathrm{VI}}\right\|$ \\
\hline 1 & $(3.4180,1.2359)$ & $(1.0264,1.2291)$ & -0.4423 \\
\hline 2 & $(3.4180,1.2359)$ & $(0.0848,0.5768)$ & -1.0735 \\
\hline 3 & $(3.4180,1.2359)$ & $(0.9909,0.8357)$ & +0.3386 \\
\hline 4 & $(3.4180,1.2359)$ & $(0.2043,0.0938)$ & +0.2411 \\
\hline 5 & $(3.2988,1.9167)$ & $(0.7325,0.6269)$ & +0.1459 \\
\hline 6 & $(3.2988,1.9167)$ & $(0.1899,0.1809)$ & +0.0124 \\
\hline 7 & $(3.2988,1.9167)$ & $(0.2453,0.2397)$ & $+7.73 \mathrm{E}-3$ \\
\hline 8 & $(3.2988,1.9167)$ & $(0.0356,0.0193)$ & +0.0225 \\
\hline 9 & $(3.2773,1.9307)$ & $(0.2453,0.2397)$ & +0.073 \\
\hline
\end{tabular}

680. Tables 11, 12, 13 and 14 show respectively the capacitor bank direction and estimation of distance between the switched capacitor bank and the monitoring location in different switching states.

\subsection{Investigating of sampling rate in estimating distance of the switched capacitor bank}

The precision of distance estimation of a switched capacitor bank is a function of the sampling rate measured by PQM in the monitoring locations. The high sampling rate causes the time between 
Table 12. Estimation of distance between the switched capacitor bank in the presence of stochastic nonliner loads in the normal switching state

\begin{tabular}{|c|c|c|c|c|c|c|}
\hline Error & $\mathrm{D}_{\text {real }}$ & $\mathrm{D}_{\text {est }}$ & $\Psi_{2}$ & $\Psi_{1}$ & $\mathrm{~K}_{\mathrm{S} . \mathrm{V}}$ & $\|\left(\mathrm{V}\left(\mathrm{t}_{\mathrm{s}}{ }^{-}, \mathrm{t}_{\mathrm{S}}{ }^{+}\right) \|\right.$ \\
\hline $9.2 \%$ & 0.1 & 0.1092 & -0.02 & -0.26 & 0.566 & $(3.418,1.235)$ \\
\hline
\end{tabular}

Table 13. Determining direction of the switched capacitor bank using IID $_{\mathrm{VI}} \mathrm{II}$ in the presence of stochastic nonliner loads in the Back-To-Back switching state

\begin{tabular}{|c|c|c|c|}
\hline Branch & IIV $\left(\mathrm{t}_{\mathrm{s}}^{-}\right) \mathrm{II}, \mathrm{IIV}\left(\mathrm{t}_{\mathrm{s}}{ }^{+}\right) \mathrm{II}$ & $\mathrm{III}\left(\mathrm{t}_{\mathrm{s}}^{-}\right) \mathrm{II}, \mathrm{III}\left(\mathrm{t}_{\mathrm{s}}{ }^{+}\right) \mathrm{II}$ & $\left\|\mathrm{D}_{\mathrm{V}_{\mathrm{II}}}\right\|$ \\
\hline 1 & $(3.4310,1.4451)$ & $(1.0264,1.2291)$ & -0.2549 \\
\hline 2 & $(3.4310,1.4451)$ & $(0.0848,0.5768)$ & -0.7586 \\
\hline 3 & $(3.4310,1.4451)$ & $(0.9909,0.8357)$ & +0.3129 \\
\hline 4 & $(3.4310,1.4451)$ & $(0.2043,0.0938)$ & +0.1888 \\
\hline 5 & $(3.3201,3.2684)$ & $(0.7325,0.6269)$ & $+5.89 \mathrm{E}-4$ \\
\hline 6 & $(3.3201,3.2684)$ & $(0.1899,0.1809)$ & $+4.23 \mathrm{E}-4$ \\
\hline 7 & $(3.3201,3.2684)$ & $(0.2453,0.2397)$ & $+7.23 \mathrm{E}-5$ \\
\hline 8 & $(3.3201,3.2684)$ & $(0.0356,0.0193)$ & $+7.55 \mathrm{E}-5$ \\
\hline 9 & $(3.2967,3.2468)$ & $(0.2453,0.2397)$ & $+7.11 \mathrm{E}-5$ \\
\hline
\end{tabular}

Table 14. Estimation of distance between the switched capacitor bank in the presence of stochastic nonliner loads in the Back-To-Back switching state

\begin{tabular}{|c|c|c|c|c|c|c|}
\hline Error & $\mathrm{D}_{\text {real }}$ & $\mathrm{D}_{\text {est }}$ & $\Psi_{2}$ & $\Psi_{1}$ & $\mathrm{~K}_{\mathrm{S} . \mathrm{V}}$ & $\|\left(\mathrm{V}\left(\mathrm{t}_{\mathrm{s}}{ }^{\circ}, \mathrm{t}_{\mathrm{S}}{ }^{+}\right) \|\right.$ \\
\hline $5.8 \%$ & 0.1 & 0.1058 & -0.044 & -0.417 & 0.732 & $(3.431,1.4451)$ \\
\hline
\end{tabular}

two successive samples to become smaller and the current and voltage changes measured immediately after switching instant to be more precise and as a result, the distance is estimated better. Tables 15 and 16 show respectively the effect of the sampling rate on estimating distance of the switched capacitor bank in normal switching and back-to-back switching states.

Manifolding the sampling rate will make the distance estimation more precise, but, it is noteworthy that in practice, careful measures should be also taken to remove the high frequency noisy signals mainly arising from the shunt capacitance of the feeder lines. The higher the sampling rate, the more complicated this filtering. This will be a drawback of increasing the sampling rate. To prevent occurrence of such cases, the sampling frequency should be limited [6]. Such a limit is basically determined by the highest frequency of the main signal during the switching transients [11]. The transient state frequency is usually in the range of $300-1000 \mathrm{~Hz}$, but increase of frequency of the transient state produced by the back-to-back switching should also be considered. As it's depicted in [18], frequency of $60 \mathrm{KHz}$ as the maximum sampling rate for algorithm of distance estimation of the capacitor bank is considered in this paper. 
Table 15. Effect of measured signals sampling rate on estimating distance in the normal switching state

\begin{tabular}{|c|c|c|c|}
\hline & $\begin{array}{c}256 \\
\text { Sample/cycle }\end{array}$ & $\begin{array}{c}512 \\
\text { Sample/cycle }\end{array}$ & $\begin{array}{c}1024 \\
\text { Sample/cycle }\end{array}$ \\
\hline$\left(\mathrm{IIV}\left(\mathrm{t}_{\mathrm{s}}^{-}\right) \mathrm{II}, \mathrm{IIV}\left(\mathrm{t}_{\mathrm{s}}{ }^{+}\right) \mathrm{II}\right)$ & $(3.4655,1.2223)$ & $(3.4659,1.2086)$ & $(3.4663,1.1947)$ \\
\hline $\mathrm{K}_{\mathrm{S} . \mathrm{V}}$ & 0.544 & 0.534 & 0.52 \\
\hline$\left(1+\Psi_{1+} \Psi_{2}\right)$ & 0.83 & 0.803 & 0.771 \\
\hline $\mathrm{D}_{\text {est }}$ & 0.1210 & 0.1149 & 0.1073 \\
\hline Error $\%$ & $21 \%$ & $14.9 \%$ & $7.3 \%$ \\
\hline
\end{tabular}

Table 16. Effect of measured signals sampling rate on estimating distance in the Back-To-Back switching state

\begin{tabular}{|c|c|c|c|}
\hline & $\begin{array}{c}256 \\
\text { Sample/cycle }\end{array}$ & $\begin{array}{c}512 \\
\text { Sample/cycle }\end{array}$ & $\begin{array}{c}1024 \\
\text { Sample/cycle }\end{array}$ \\
\hline$\left(\mathrm{IIV}\left(\mathrm{t}_{\mathrm{s}}^{-}\right) \mathrm{II}, \mathrm{IIV}\left(\mathrm{t}_{\mathrm{s}}^{+}\right) \mathrm{II}\right)$ & $(3.4955,1.4689)$ & $(3.4960,1.4567)$ & $(3.4964,1.4459)$ \\
\hline $\mathrm{K}_{\mathrm{S} . \mathrm{V}}$ & 0.724 & 0.714 & 0.705 \\
\hline$\left(1+\Psi_{1+} \Psi_{2}\right)$ & 0.65 & 0.62 & 0.593 \\
\hline $\mathrm{D}_{\mathrm{est}}$ & 0.1262 & 0.1187 & 0.1121 \\
\hline Error $\%$ & $26.2 \%$ & $18.7 \%$ & $12.1 \%$ \\
\hline
\end{tabular}

\section{Comparison of the Results between}

\section{the Proposed Algorithm whit Pervious Methods}

In this section, toward determining the location of a 3-phase switched capacitor bank (300 (kvar)) at bus 633, the results taken from algorithm based on the space vector is compared with the algorithm based on each phase calculating in the 13-bus network and under the same conditions, in the simplest switching state (normal switching) [10].

Regarding the fact that capacitor bank switching can happen at every instant and in every situation, and since the proposed algorithm should cover all existing states and times, thus two different switching instants (switching in the voltage peak and switching at the instant of voltage zero crossing) are compared.

Table 17 shows the results obtained from determining direction of switched capacitor bank at bus 633 at the instant when voltage in phase (b) pass through the peak (ts=0.5222) in the method based on each phase and the method based on space vector analysis.

According to Fig. 15, since the switched capacitor bank is located at bus 633, thus the calculated index in branches (1) and (2) should be negative and in other branches should be positive. Moreover, the index value in branch (2) should be larger than the one in branch (1).

According to Table 17, at the instant when voltage passing the peak, both indices $\mathrm{D}_{\mathrm{VI}}$ and $I I \mathrm{D}_{\mathrm{VI}} I$ identified the switched capacitor bank direction correctly.

The results obtained from finding direction of switched capacitor bank at the instant when voltage of phase (b) at zero crossing instant by two indices $\mathrm{D}_{\mathrm{VI}}$ and $\mathrm{IID}_{\mathrm{VI}} \mathrm{Il}$ are shown in Table 18.

It can be seen from the highlighted values in Table 18 that index identified the switched capacitor bank direction correctly but $\mathrm{D}_{\mathrm{VI}}$ index identified mistakenly the switched capacitor bank direction in 
Table 17. Comparison of results in determining direction of switched capacitor bank using indices $\mathrm{D}_{\mathrm{VI}}$ and IID $\mathrm{D}_{\mathrm{VI}} \mathrm{II}$ (switching in phase (B) peak instant)

\begin{tabular}{|c|c|c|c|c|}
\hline \multirow{2}{*}{ Branch } & \multicolumn{2}{|c|}{ state(a) } & \multicolumn{2}{c|}{ state(b) } \\
\cline { 2 - 5 } & $\mathrm{D}_{\mathrm{VI}}$ & Sign & IID $_{\mathrm{VI}}$ II & Sign \\
\hline 1 & -0.6240 & Negative & -0.4933 & Negative \\
\hline 2 & -1.3518 & Negative & -1.1260 & Positive \\
\hline 3 & +0.4520 & Positive & +0.3199 & Positive \\
\hline 4 & +0.3155 & Posetive & +0.2496 & Positive \\
\hline 5 & +0.2887 & Positive & +0.1456 & Positive \\
\hline 6 & +0.0521 & Posetive & +0.0145 & Positive \\
\hline 7 & --- & --- & -- & -- \\
\hline 8 & +0.0236 & Positive & +0.0222 & --- \\
\hline 9
\end{tabular}

Table 18. Comparison of the results obtained from finding direction of switched capacitor bank by two indices $D_{\mathrm{VI}}$ and $\mathrm{IID}_{\mathrm{VI}} \mathrm{II}$ (switching at the instant when voltage of phase (B) at zero crossing instant)

\begin{tabular}{|c|c|c|c|c|}
\hline \multirow{2}{*}{ Branch } & \multicolumn{2}{|c|}{ state(a) } & \multicolumn{2}{c|}{ state(b) } \\
\cline { 2 - 5 } & $\mathrm{D}_{\mathrm{VI}}$ & Sign & IID $_{\mathrm{VI}}$ II & Sign \\
\hline 1 & $-1.79 \mathrm{E}-5$ & Negative & -0.3437 & Negative \\
\hline 2 & $-3.13 \mathrm{E}-4$ & Negative & -0.6749 & Posetive \\
\hline 3 & $+2.69 \mathrm{E}-5$ & Posetive & +0.3564 & Posetive \\
\hline 4 & $+3.58 \mathrm{E}-4$ & Posetive & +0.0528 & Posetive \\
\hline 5 & $-3.36 \mathrm{E}-4$ & Negative & +0.0806 & Posetive \\
\hline 6 & $+3.64 \mathrm{E}-6$ & Posetive & +0.0355 & Posetive \\
\hline 7 & --- & --- & -- & --- \\
\hline 8 & $+4.74 \mathrm{E}-5$ & Posetive & +0.0179 & -- \\
\hline 9
\end{tabular}

branch (5) instead of branch (2).Comparing Tables 17 and 18, it can be concluded that the index based on the slope of the voltage and current space vectors $\left({ }^{I I D} D_{\mathrm{VI}} I\right)$, in spite of to the index based on the slope of the voltage and current in each phase, identified correctly the switched capacitor bank direction, because all three-phase quantities contribute to the magnitude of the space vector and this method is almost independent from the switching instant.

Table 19 shows the results obtained from estimation of distance between the switched capacitor bank at bus 633 and the monitoring location at bus 632 at the instant when the voltage of phase (b) passing the peak value.

In simulations, the distance between the switching capacitor bank at bus 633 and the monitoring location at bus 632 is considered as 0.1 mile.

As it can be seen in Table 19, unlike to the previous proposed methods, considering the reactance laterals branches, the distance between the switched capacitor bank and the monitoring location at the 
Table 19. Comparison of the results obtained from estimation of distance between the switched capacitor bank at the instant when the voltage passing the peak

\begin{tabular}{|c|c|c|c|l|}
\hline Error & $\mathrm{D}_{\text {est }}$ & $\left(\Psi_{1}, \Psi_{2}\right)$ & $\mathrm{K}$ & \\
\hline $34 \%$ & 0.1340 & $(0,0)$ & 0.5 & $\begin{array}{l}\text { distance Estimated in the method based } \\
\text { on each phase }\end{array}$ \\
\hline $7.3 \%$ & 0.1073 & $(-0.201,-0.028)$ & 0.52 & $\begin{array}{l}\text { distance Estimated in the method based } \\
\text { on space vector(proposed method) }\end{array}$ \\
\hline
\end{tabular}

Table 20. Comparison of the results obtained from estimation of distance of the switched capacitor bank at the instant when the voltage of phase (B) passing through the zero

\begin{tabular}{|c|c|c|c|l|}
\hline Error & $\mathrm{D}_{\text {est }}$ & $\left(\Psi_{1}, \Psi_{2}\right)$ & $\mathrm{K}$ & \multicolumn{1}{|c|}{ Condition } \\
\hline $58.7 \%$ & 0.1587 & $(0,0)$ & 0.592 & $\begin{array}{l}\text { distance Estimated in the method based } \\
\text { on each phase }\end{array}$ \\
\hline $9.5 \%$ & 0.1095 & $(-0.32,-0.01)$ & 0.61 & $\begin{array}{l}\text { distance Estimated in the method based } \\
\text { on space vector(proposed method) }\end{array}$ \\
\hline
\end{tabular}

instant when the voltage phase (b) passing through the peak is estimated with an accepTable error in the method based on each phase and the method based on the space vector.

Table 20 shows the results obtained from estimation of distance between the switched capacitor bank at bus 633 and the monitoring location at bus 632 at the zero crossing instant of phase b.

Comparing the results obtained from Table 20, it can be seen that the error of distance estimation at the zero crossing instant in the method based on each phase is higher than the error of distance estimation in the method based on the space vector dramatically.

\section{Conclusion}

This paper proposed an efficient and novel technique for assessment of the direction of switched capacitor bank and estimating its distance from the monitoring location in real distribution systems. In this method, at first the direction in which the capacitor is switched determined, based on the slopes of the voltage and current space vectors immediately after and before switching. Then, the location of the switched capacitor bank is determined using initial changes in magnitude of the space vector of the current and voltage after instant of switching as well as estimation of the inductance of the desired line. The validity and effectiveness of the proposed algorithm, in different switching states (normal and back-to-back), considering stochastic nonlinear loads and different sampling rate were studied and Simulation results show lower and accepTable error in locating the switched capacitor bank in distribution systems compared than other previous conventional method. The advantages of the proposed method are as follows:

- Due to calculating of proposed indices based on switching transient, other parameters such as harmonics, load changes, faults, etc. can't have significant error in method accuracy. However, in the previous works, the introduced indices have affected dramatically by the above mentioned factors. 
- The proposed method is applied based on switching transient voltage and current in the switching instant exactly. Therefore, this method can determined the switched capacitor bank and estimate its location from the monitoring location immediately after the switching.

- Application of space vector magnitude of current and voltage improved the distance estimation algorithm function due to using the information of three phases in the calculations and the estimation of distance will be independent from the switching instant.

- The required calculations for determining the switched capacitor banks are simple and can be applied in real distribution systems.

\section{References}

[1] Greenwood A. Electrical transients in power systems, 1991.

[2] Das J. Analysis and control of large-shunt-capacitor-bank switching transients, IEEE Transactions on Industry Applications, 2005, 41(6), 1444-1451.

[3] Sochuliakova D., Niebur D., Nwankpa C., Fischl R., Richardson D. Identification of capacitor position in a radial system, IEEE Transactions on Power Delivery, 1999, 14(4), 1368-1373.

[4] Chang G., Shih M., Chu S., Thallam R. An efficient approach for tracking transients generated by utility shunt capacitor switching, IEEE Transactions on Power Delivery, 2006, 21(1), $510-512$.

[5] Kim J. W., Grady M., Arapostathis A., Soward J.C., Bhatt S.C. A time-domain procedure for locating switched capacitors in power distribution systems, EEE Transactions on Power Delivery, 2002, 17(4), 1044-1049.

[6] Hur K., Santoso S. Distance estimation of switched capacitor banks in utility distribution feeders, IEEE transactions on power delivery, 2007, 22(4), 2419-2427.

[7] Hur K., Santoso S. On two fundamental signatures for determining the relative location of switched capacitor banks, IEEE Transactions on Power Delivery, 2008, 23(2), 1105-1112.

[8] Hong Y.Y., Chen B.Y. Locating switched capacitor using wavelet transform and hybrid principal component analysis network, IEEE Transactions on Power Delivery, 2007, 22(2), 1145-1152.

[9] Abu-Elanien A.E., Salama M. A wavelet-ANN technique for locating switched capacitors in distribution systems, IEEE Transactions on Power Delivery, 2009, 24(1), 400-409.

[10] Khani H., Moallem M., Sadri S., Dolatshahi M. A new method for online determination of the location of switched capacitor banks in distribution systems, IEEE Transactions on Power Delivery, 2001, 26(1), 341-351.

[11] Saadatpoor A., Tabesh A., Iravani R. Space-vector slope-based method for fast locating of switched capacitors in power systems, Generation, Transmission \& Distribution, IET, 2013, 7(1), 5260 .

[12] Kersting W.H. Radial distribution test feeders, Power Engineering Society Winter Meeting, IEEE, 2001.

[13] Manitoba, Research Centre, PSCAD/EMTDC, Electromagnetic transients program including dc systems, 1994.

[14] Karimi M., Mokhtari H., Iravani M.R. Wavelet based on-line disturbance detection for power quality applications, IEEE Transactions on Power Delivery, 2000, 15(4), 1212-1220.

$$
-995-
$$


[15] Tan R.H., Ramachandaramurthy V.K. Capacitor bank switching classification using scale selection continuous wavelet transform, Power Electronics and Drive Systems, PEDS International Conference IEEE, 2009.

[16] Lin W.M., Wu C.H., Lin C.H., Cheng F.S. Detection and classification of multiple powerquality disturbances with wavelet multiclass SVM, IEEE Transactions on Power Delivery, 2008, 23(4), 2575-2582.

[17] Krause P.C., Wasynczuk O., Sudhoff S.D., Pekarek S. Analysis of electric machinery and drive systems, 2013.

[18] Tabatabaei S.M., Vahidi B., Hosseinian S.H., Ahadi S.M. Locating the effect of switched capacitor in distribution system using support vector machine, Sci. Int. (Lahore), 2014, 26(2), 605611 . 